\title{
Botulinum 007 - gerührt, nicht geschüttelt
}

\begin{abstract}
Was bei einer Behandlung mit Botulinumtoxin unbedingt beachtet werden muss, lesen Sie in folgendem Tipp.
\end{abstract}

Bei der Verwendung von Botulinumtoxin $\left(\right.$ Botox $\left.^{\circledR}\right)$ ist es besonders wichtig, dass die das Medikament aufziehenden Schwestern oder MFAs beachten, dass beim Suspendieren die entstehende Lösung nicht durch heftige Bewegungen inaktiviert wird. Wird wie sonst bei der Zubereitung einer Medikamenteninfusion „geschüttelt“ oder „geklopft“, kommt es zur Denaturierung des Wirkstoffs und damit zu einer teuren aber ineffektiven Behandlung.

Um diese „Reflexe“ zu vermeiden, hat sich bei uns ein lockerer Spruch etabliert, der in Umkehrung des Mottos von James Bond bei seiner berühmten Martini-Bestellung auf diese Situation übertragen wird: „Gerührt, nicht geschüttelt“ lautet die Devise!

\section{PD Dr. Andreas Wiedemann, Witten}

Korrespondenz:

PD Dr. Andreas Wiedemann

Urologische Klinik

Evangelisches Krankenhaus

im Diakoniewerk Ruhr gGmbH

Lehrstuhl für Geriatrie

der Universität Witten/Herdecke

Pferdebachstr. 27

58455 Witten

Tel.: +49/2302/175-2521

awiedemann@diakonie-ruhr.de

Interessenkonflikte:

Beratungstätigkeit: Dr. Pfleger, Pfizer; Vortragstätigkeit: Allergan, AMS Deutschland, Astellas, Berlin-Chemie, Jansen, Lilly Deutschland, Dr. Pfleger, Pfizer, PohlBoskamp; Studienfinanzierung: AMS Deutschland

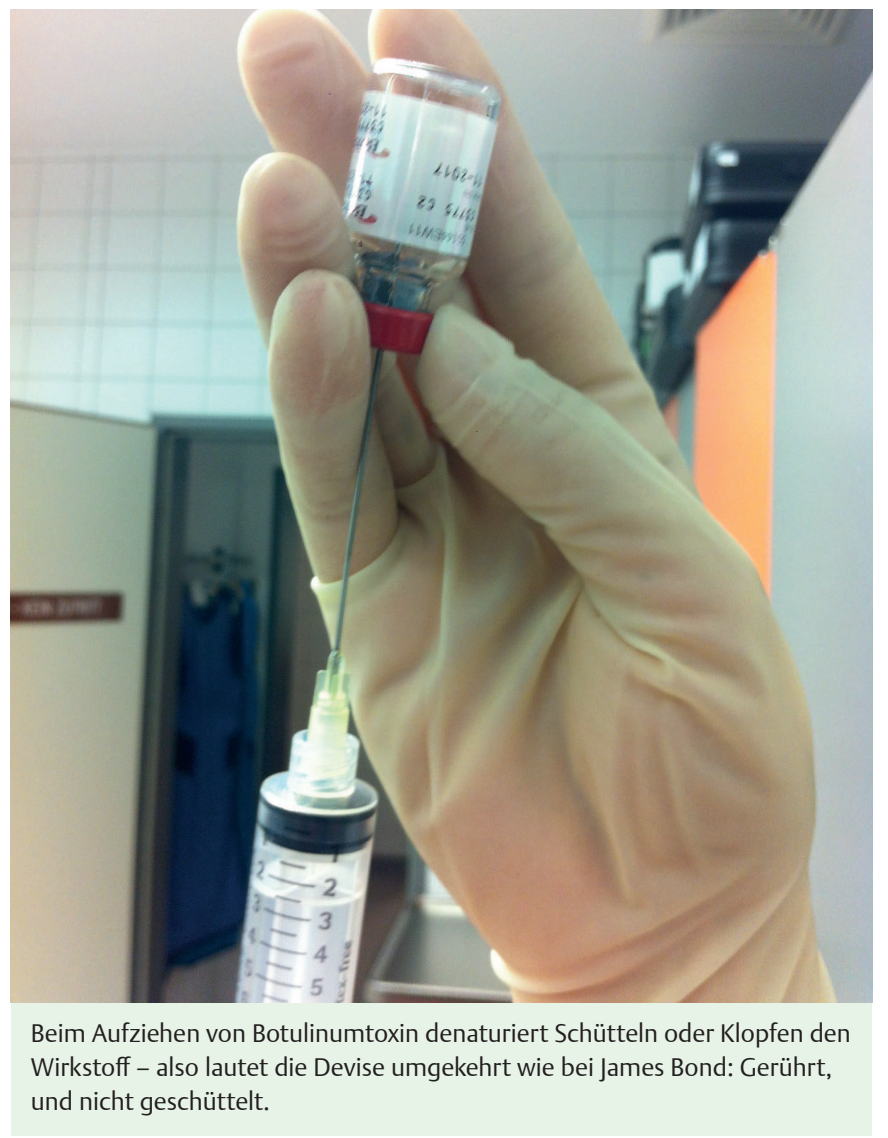

